\title{
Demographic characteristics and quality of life of patients with unexplained complaints: a descriptive study in general practice
}

\author{
Hèlen Koch · Marloes A. van Bokhoven - Gerben ter Riet · Trudy van der Weijden • \\ Geert Jan Dinant · Patrick J. E. Bindels
}

Accepted: 6 August 2007/Published online: 26 September 2007

(C) Springer Science+Business Media B.V. 2007

\begin{abstract}
Objective About $13 \%$ of GPs' consultations involve unexplained complaints (UCs). These complaints can progress to chronic conditions like medically unexplained symptoms, chronic functional symptoms or somatoform disorders. Little is known about the demographic characteristics and quality of life of patients with early stage UCs. Our study objective was to describe these characteristics. Additionally we compared them with other patient groups to serve as a frame of reference.

Methods Descriptive study in general practices. Patients with early stage UCs who had not had elaborate diagnostic investigations were included. Demographic characteristics were compared to a Dutch general practice population. Quality of life scores were measured with the RAND-36 and compared to another Dutch general practice population and to depressed patients.

Results Data of 466 patients were available for analysis. Mean age was 44 years and $74 \%$ were females, mostly higher educated. Of the patients, $63 \%$ presented with unexplained fatigue. On average, quality of life was poor
\end{abstract}

H. Koch $(\bowtie) \cdot$ G. te. Riet · P. J. E. Bindels

Department of General Practice, Division of Clinical Methods \&

Public Health, Academic Medical Center-University

of Amsterdam, P. O. Box 22660, 1100 DD Amsterdam,

The Netherlands

e-mail: h.koch@amc.uva.nl

M. A. van Bokhoven - T. van der Weijden - G. J. Dinant Department of General Practice, University of Maastricht, Care and Public Health Research Institute (CAPHRI),

Maastricht, The Netherlands

G. te. Riet

Horten Centre, University of Zurich, Zurich, Switzerland (mean RAND-36 domain scores 37-73), also in comparison with other groups.

Conclusion General practice patients presenting with UCs have a remarkably poor quality of life. Future research should explore how early identification of patients at risk of developing chronicity can take place. Awareness of potential poor quality of life may influence GPs' medical decision making.

Keywords Descriptive study $\cdot$ Fatigue $\cdot$ Family practice . Quality of life · Unexplained complaints

\section{Introduction}

A patient's complaints are said to be unexplained if the general practitioner (GP) cannot decide on a specific diagnosis after adequate history taking, physical examination and careful consideration of the patient's psychosocial context [1]. On average, $13 \%$ of consultations involve complaints considered unexplained by Dutch GPs [2]. These unexplained complaints often concern fatigue, abdominal and musculoskeletal complaints.

It is often assumed that unexplained complaints are mild and self-limiting, because patients do often not revisit their GP for them after a first consultation [3, 4]. However, an unexplained complaint can be a first sign of somatic or psychosocial pathology or a precursor of more chronic unexplained complaints such as chronic medically unexplained symptoms (MUS), chronic functional symptoms or somatoform disorders [5].

Patients with chronic unexplained conditions often have high levels of medication and other healthcare use and frequently show significant psychological distress [6]. Patients with multiple medically unexplained symptoms 
(MMUS) have impaired quality of life [7]. Furthermore, patients often do not feel taken seriously, do not feel helped and feel treated as malingerers. They, therefore, tend to lose trust in their GPs [8]. In brief, the long-term consequences of many unexplained complaints are unfavourable.

GPs too consider unexplained complaints problematic. One study found that in consultations with such patients GPs feel frustrated and helpless though devoted to help [9].

Research on unexplained complaints is increasing. So far, most research has focused on patients with chronic consequences of unexplained complaints. This research varies from discussions on nomenclature and taxonomy [10-12], to research on the characterization of these patient groups [13, 14] and possible treatment options [15-17]. Little is known about patients with unexplained complaints in their early stages. We performed this study to describe the demographic characteristics and quality of life of patients with early stage unexplained complaints. To provide some frame of reference, we compared these descriptive measures for the unexplained complaints to those of an unselected group of patients visiting their GP, and a group of depressed patients. For practitioners, better delineation, in terms of quality of life, of a group of patients that frequently seeks their help may sensitize them to consider more structured monitoring in order to achieve a firmer diagnosis be it somatic, psychological, or psychosocial.

\section{Methods}

GPs and patients

GPs were recruited from the southern and the western part of the Netherlands. GPs were given the Dutch College of General Practitioners' definition of unexplained complaints: those complaints that remain of unclear origin for the GP after adequate history taking, physical examination and careful consideration of the patient's psychosocial context [1]. This definition supposes that complaints are labelled "unexplained" early on in the clinical episode before elaborate investigations were performed.

Between February 2002 and December 2003, participating GPs included adult patients, presenting with a complaint that the GP designated as "unexplained" at the end of the first consultation. Patients who had presented with the same complaint in the previous 6 months were not included. Patients were eligible if they presented with fatigue, abdominal complaints, musculoskeletal complaints, weight changes or itch as their main complaint.
Individual GPs decided whether a complaint was "unexplained". There was no standardization of this process other than that implied by the Dutch College of General Practitioners' definition. GPs invited patients to participate in the study at the end of the consultation.

Informed consent procedure and medical ethics committees

All participating patients gave written informed consent after having read information provided by the GP directly after the consultation. The medical ethics committees of the University of Amsterdam and Maastricht University approved the study protocol.

\section{Data collection: study population}

The data for this study were collected as part of baseline measurements for a randomized diagnostic trial on unexplained complaints in general practice [18]. After the entry consultation, patients filled out a questionnaire on demographic characteristics. The RAND 36-item Health Survey (RAND-36) was used to measure generic healthrelated quality of life. The RAND-36 [19] is a Dutch version of the Medical Outcome Study 36-item Short Form Health Survey (SF-36) [20] and is composed of 36 questions and standardized response choices, organized into eight multi-item scales (domains). These eight domains are: physical functioning $(\mathrm{PF})$, role limitations due to physical health problems (RP), social functioning (SF), general mental health (MH), role limitations due to emotional problems (RE), vitality (VT), bodily pain (BP) and general health perception (GH). Raw RAND-36 scores on the eight domains are linearly converted to 0 100 scales with higher scores indicating better quality of life.

Data collection: reference populations

\section{Reference population for comparison of demographic characteristics}

The demographic characteristics of a Dutch general practice population were taken from the second Dutch National Survey of General Practice, which is a large representative population-based survey that takes place every 10 years. Methods of this study have been published elsewhere [21]. Briefly, this national survey contains data about health and healthcare-related behaviour of 375,899 persons, registered in 104 practices with 195 GPs in 2001. 
Reference populations for comparison of quality of life

The results section of this manuscript shows that the quality of life of patients with early stage unexplained complaints is poor. Our initial objective was purely descriptive. However, when such low quality of life figures were found, we felt the need to compare these to other patient groups. First, we wondered whether maybe all patients consulting their GP would have such low quality of life figures and therefore compared the unexplained complaints group with a Dutch general practice population. We also thought that maybe our patient population included a lot of depressed patients which could explain the poor quality of life and therefore also compared our quality of life figures with those of a population of depressed patients.

Figures of the Dutch general practice population came from a study on functional status, health problems, age and comorbidity in primary care patients [22]. In this study 60 GPs from 43 general practices handed out a written questionnaire to 100 patients of 18 years and older, consecutively visiting their practice. In total 4,024 patients responded.

Figures of the depressed patients came from the Netherlands Mental Health Survey and Incidence Study (NEMESIS). This NEMESIS survey, was based on a random sample drawn from the Dutch general adult population aged 18-64 $(n=7,076)$ of whom 204 had been diagnosed with a major depression within the past month [23].

\section{Statistical analysis}

First, we compared the demographic characteristics of the five unexplained complaint categories to each other. Those of the total UC study population were compared to those of a Dutch general practice population. Differences were tested using the Fisher's exact test.

Second, mean domain scores on the RAND-36 were compared for each of the five unexplained complaint groups using linear regression with the "fatigue" complaint group as the reference category. We calculated robust variance estimates (Huber-White sandwich estimator) [24] to allow for potential dependence of quality of life scores within a single GP.

Lastly, we compared mean domain scores of the total UC study population to those of a Dutch general practice population sample and to a random sample of depressed patients. Differences were statistically tested with $t$-tests in which equal variances were not assumed. Analyses were performed using STATA, version 9.2.

\section{Results}

General characteristics of the study group

Of the 91 GPs who intended to participate, 18 dropped out before including any patients. They predominantly reported lack of time as the reason for drop out. Ten GPs did not include any patients during the inclusion period, although they did not formally drop out. Thus, 63 GPs (69\%) included 513 patients with unexplained complaints (range: 1-36 patients per GP). Questionnaires from 466 (91\%) patients were available for analysis. Forty-seven patients stopped their participation to the study or did not fill out this particular questionnaire.

Demographic characteristics of the study group

The demographic characteristics are summarized in Table 1, for the total UC study population, per complaint group and for the Dutch general practice population. The mean age of the total UC study population was 44 years (interquartile range 31-55) and 74\% were women. Most patients had completed secondary or higher level education $(91 \%)$ and were married or living together with a partner $(71.5 \%)$.

The main reason for encounter was fatigue $(63.3 \%)$ and only few patients with weight changes or itch were included. In all further analyses, these latter two groups were combined into an "other complaints" group.

Patients with musculoskeletal complaints were significantly older and less educated than patients with fatigue or abdominal complaints $(P<0.05)$.

Compared to patients from the Dutch general practice population (second Dutch National Survey of General Practice), unexplained complaint patients were more likely to be women ( $74 \%$ vs. $51 \%$ ), older ( $46 \%$ vs. $33 \%$ in the age group 40-64) and more highly educated (91\% vs. 65\% secondary or higher level education). These differences were statistically significant $(P<0.05)$.

Quality of life of the total UC study population and per unexplained complaint group

The overall quality of life for the total UC study population was poor (Table 2). All domains showed a mean score of less than 70 (on a scale from 0 to 100), except Physical Functioning (mean 73.4). The lowest score was in the Role Functioning Physical domain (mean 37.2). Also the Vitality domain scored low (mean 40.5) both in the total UC study population and in the separate complaint groups. 
Table 1 Demographic characteristics of the total UC study population, per complaint group and of a Dutch general practice population

\begin{tabular}{|c|c|c|c|c|c|c|c|}
\hline $\begin{array}{l}\text { Demographic } \\
\text { characteristic }\end{array}$ & Categories & $\begin{array}{l}\text { Total UC study } \\
\text { population } \\
\%(n=466)\end{array}$ & $\begin{array}{l}\text { Fatigue } \\
\%(n=295)\end{array}$ & $\begin{array}{l}\text { Abdominal } \\
\text { complaints } \\
\%(n=60)\end{array}$ & $\begin{array}{l}\text { Musculoskeletal } \\
\text { complaints } \\
\%(n=69)\end{array}$ & $\begin{array}{l}\text { Other } \\
\text { complaint } \\
\text { groups } \\
\%(n=42)\end{array}$ & $\begin{array}{l}\text { Dutch GP } \\
\text { population } \\
\%(n=3,85,461)\end{array}$ \\
\hline \multirow[t]{2}{*}{ Sex } & Male & 26.4 & 26.1 & 25 & 24.6 & 33.3 & 49.5 \\
\hline & Female & $73.6^{\mathrm{a}}$ & 73.9 & 75 & 75.4 & 66.7 & 50.5 \\
\hline \multirow[t]{5}{*}{ Age } & Mean (years) & 44.2 & 41.8 & 42.3 & $52.2^{\mathrm{b}}$ & 50.3 & Unknown \\
\hline & $0-19$ & 4.9 & 6.1 & 6.7 & 1.1 & 0 & 23.4 \\
\hline & $20-39$ & 37.1 & 42 & 45 & 13 & 30.9 & 30.4 \\
\hline & $40-64$ & $45.9^{\mathrm{a}}$ & 41.7 & 40 & 66.7 & 50 & 33 \\
\hline & $65+$ & 12 & 10.2 & 8.3 & 18.8 & 19.1 & 13.2 \\
\hline \multirow[t]{4}{*}{ Educational level } & None & 1 & 0 & 0 & $4.3^{b}$ & 2.4 & 16 \\
\hline & Elementary & 9 & 7.5 & 3.3 & $17.4^{\mathrm{b}}$ & 14.3 & 18.9 \\
\hline & Secondary & $68.9^{\mathrm{a}}$ & 68.1 & 80 & $59.5^{\mathrm{b}}$ & 64.3 & 48.1 \\
\hline & Higher & $22.1^{\mathrm{a}}$ & 24.4 & 16.7 & 18.8 & 19 & 17 \\
\hline \multirow[t]{2}{*}{ Marital state } & Single & 28.5 & 29.8 & 20 & 30.4 & 28.6 & Unknown \\
\hline & Married/cohabiting & 71.5 & 70.2 & 80 & 69.5 & 71.4 & Unknown \\
\hline \multirow[t]{2}{*}{ Insurance Type } & Public & 65.2 & 65.8 & 68.3 & 69.6 & 50 & 67.4 \\
\hline & Private & 34.8 & 34.2 & 31.7 & 30.4 & 50 & 32.6 \\
\hline \multirow[t]{2}{*}{ Nationality } & Dutch & 95.3 & 96.3 & 96.7 & 91.3 & 93 & 86.2 \\
\hline & Not Dutch & 4.7 & 3.7 & 3.3 & 8.7 & 7 & 13.8 \\
\hline \multirow[t]{2}{*}{ Region of the Netherlands } & West & 56.4 & 57.6 & 46.7 & 62.3 & 52.4 & Unknown \\
\hline & South & 43.6 & 42.4 & 53.3 & 37.7 & 47.6 & Unknown \\
\hline
\end{tabular}

a $P<0.05$ (Fisher's exact test, reference group is GP population)

b $P<0.05$ (Fisher's exact test, reference groups are fatigue and abdominal complaints)

Table 2 Quality of life of the total UC study population and per complaint group

\begin{tabular}{|c|c|c|c|c|c|c|c|c|}
\hline \multirow{3}{*}{$\begin{array}{l}\mathrm{N} \\
\text { Domains RAND-36 }\end{array}$} & \multirow{3}{*}{$\begin{array}{l}\text { All } \\
466 \\
\text { Mean }\end{array}$} & \multirow{3}{*}{$\begin{array}{l}\text { Fatigue } \\
295 \\
\text { Mean }\end{array}$} & \multirow{2}{*}{\multicolumn{2}{|c|}{$\frac{\text { Abdominal }}{60}$}} & \multirow{2}{*}{\multicolumn{2}{|c|}{$\begin{array}{l}\text { Musculoskeletal } \\
69\end{array}$}} & \multirow{2}{*}{\multicolumn{2}{|c|}{$\frac{\text { Other }}{42}$}} \\
\hline & & & & & & & & \\
\hline & & & Mean & $\Delta(95 \% \mathrm{CI})$ & Mean & $\Delta(95 \% \mathrm{CI})$ & Mean & $\Delta(95 \% \mathrm{CI})$ \\
\hline Physical functioning & 73.4 & 73.3 & 81.3 & $8.1(2.2 \text { to } 14.0)^{\mathrm{a}}$ & 62.2 & $-8.0(-14.8 \text { to }-1.3)^{\mathrm{a}}$ & 76.3 & $3.0(-4.3$ to 10.4$)$ \\
\hline Social functioning & 66.5 & 62.5 & 70.8 & $8.3(-0.2$ to 16.9$)$ & 76.4 & $13.9(6.9 \text { to } 21.0)^{\mathrm{a}}$ & 72 & $9.5(-0.7$ to 19.7$)$ \\
\hline Role functioning physical & 37.2 & 31.5 & 56.3 & $24.7(11.9 \text { to } 37.5)^{\mathrm{a}}$ & 39 & $7.5(-3.5$ to 18.5$)$ & 47 & 15.4 ( -6 to 31.4$)$ \\
\hline Role functioning emotional & 60.2 & 54.1 & 74.4 & $20.3(9.0 \text { to } 31.6)^{\mathrm{a}}$ & 74.2 & $20.1(6.6 \text { to } 33.6)^{\mathrm{a}}$ & 59.3 & $5.2(-10.4$ to 20.8$)$ \\
\hline Mental health & 63.8 & 61.8 & 69.4 & $7.6(2.3 \text { to } 12.9)^{\mathrm{a}}$ & 67.9 & $6.1(1.1 \text { to } 11.1)^{\mathrm{a}}$ & 62.9 & $1.0(-6.8$ to 8.8$)$ \\
\hline Vitality & 40.5 & 33.6 & 53.7 & $20.1(15.1 \text { to } 25.1)^{\mathrm{a}}$ & 54.1 & $20.5(13.8 \text { to } 27.2)^{\mathrm{a}}$ & 48.5 & $14.9(8.2 \text { to } 21.5)^{\mathrm{a}}$ \\
\hline Bodily pain & 67.7 & 72.7 & 61.7 & $-10.0(-15.9 \text { to }-6)^{\mathrm{a}}$ & 55.5 & $-17.2(-25.2 \text { to }-9.2)^{\mathrm{a}}$ & 61.3 & $-11.4(-21.5 \text { to }-1.2)^{\mathrm{a}}$ \\
\hline General health & 55.7 & 55.2 & 61.1 & $5.9(3.4 \text { to } 8.4)^{\mathrm{a}}$ & 53.8 & $-1.4(-3.6$ to 0.8$)$ & 54.3 & $-0.9(-5$ to 3.3$)$ \\
\hline
\end{tabular}

Differences $(\Delta)$ indicate differences with the fatigue subgroup, where the mean of the fatigue subgroup was subtracted from the other subgroup's mean

Confidence intervals $(95 \% \mathrm{CI})$ were calculated using the Huber-White sandwich variance estimator which accounts for within physician correlation (for details, see main text)

${ }^{a} P<0.05$ (linear regression, reference group is fatigue)

Except for the Physical Functioning and Bodily Pain scales, patients with unexplained fatigue significantly scored the worst $(P<0.05)$ in every domain, especially on the Role Functioning Physical domain (mean 31.5). Patients with musculoskeletal complaints showed the significantly lowest score on Physical 
Table 3 Comparison of RAND-36 scores of different patient groups

\begin{tabular}{|c|c|c|c|c|c|}
\hline \multirow{4}{*}{$\begin{array}{l}\text { Domains RAND-36 } \\
\text { Age } \\
N\end{array}$} & \multirow{4}{*}{$\begin{array}{l}\text { Total UC study population } \\
18-87 \\
466 \\
\text { Mean }\end{array}$} & \multirow{2}{*}{\multicolumn{2}{|c|}{$\frac{\text { Dutch GP population }}{18-80+}$}} & \multicolumn{2}{|c|}{ Depression } \\
\hline & & & & \multicolumn{2}{|l|}{$18-64$} \\
\hline & & \multicolumn{2}{|l|}{4,024} & \multicolumn{2}{|l|}{204} \\
\hline & & Mean & $\Delta(95 \% \mathrm{CI})$ & Mean & $\Delta(95 \% \mathrm{CI})$ \\
\hline Physical functioning & 73.4 & 78.5 & $5.1(2.9 \text { to } 7.3)^{\mathrm{a}}$ & 81.2 & $7.8(3.9 \text { to } 11.7)^{\mathrm{a}}$ \\
\hline Social functioning & 66.5 & 74.5 & $8(5.4 \text { to } 10,6)^{\mathrm{a}}$ & 62.5 & $-4(-8.4 \text { to } 0.4)^{\mathrm{a}}$ \\
\hline Role functioning physical & 37.2 & 62.4 & $25.2(21.5 \text { to } 28.9)^{\mathrm{a}}$ & 63.4 & $26.2(19.3 \text { to } 33.1)^{\mathrm{a}}$ \\
\hline Role functioning emotional & 60.2 & 75 & $14.8(10.6 \text { to } 19.0)^{\mathrm{a}}$ & 42.6 & $-17.6(-24.6 \text { to }-10.6)^{a}$ \\
\hline Mental health & 63.8 & 69.6 & $5.8(4.0 \text { to } 7.6)^{\mathrm{a}}$ & 46.6 & $-17.2(-20.4 \text { to }-14.0)^{\mathrm{a}}$ \\
\hline Vitality & 40.5 & 58.5 & $18(16.1 \text { to } 19.9)^{\mathrm{a}}$ & 40.3 & $-0.2(-3.6$ to 3.2$)$ \\
\hline Bodily pain & 67.7 & 68.4 & 0.7 (-1.7 to 3.1$)$ & 68 & $0.3(-4.3$ to 4.9$)$ \\
\hline General health & 55.7 & 65.7 & $10(8.9 \text { to } 11.1)^{\mathrm{a}}$ & 55.7 & $0(-3.2$ to 3.2$)$ \\
\hline
\end{tabular}

Differences $(\Delta)$ indicate differences with the total UC study population, where the mean of the total UC study population was subtracted from the other patient group's mean

95\% CI: 95\% confidence interval

${ }^{a} P<0.05$ ( $t$-test with equal variances not assumed, reference group is total UC study population)

Functioning (mean 62.2) and Bodily Pain (mean 55.5) $(P<0.05)$.

Comparison of quality of life with other patient groups

Table 3 shows that the total UC study population scored lower on all domains than the Dutch general practice population. These differences were statistically significant $(P<0.05)$ for all domains except Bodily Pain.

Patients from the depression group scored significantly lower on the Role Functioning Emotional and Mental Health domains. On all the other domains the total UC study population scored equally high or significantly lower (Physical Functioning and Role Functioning Physical, $P<0.05)$ than patients from the depression group. In other words, unexplained complaint patients scored lowest on predominantly physically oriented domains, whereas depressed patients scored lowest on predominantly mentally/emotionally oriented domains.

\section{Discussion}

Our findings indicate that patients with early stage unexplained complaints are mainly women in their forties, with secondary or higher education levels and with an overall remarkably poor quality of life. Their quality of life in all but one domain of the RAND-36 is significantly worse than that of patients from a general practice population, even taking into account that such a population also includes (around $13 \%$ of) unexplained complaint patients. Patients with unexplained complaints predominantly score badly on physically oriented domains, compared to depressed patients, who predominantly score badly on mental/emotional oriented domains. For the remaining domains they score on a comparably low level. Therefore, practitioners may consider to pay attention to quality of life aspects of patients with early stage unexplained complaints, even though this may not always lead to a firmer diagnosis or instant improvement in treatment options for most patients. A more intense monitoring of these patients could, however, be advised.

The total UC study population scored very low on the Vitality domain of the RAND-36 (mean 40.5). This domain consists of questions regarding spirit and energy. The Vitality domain of the SF/RAND-36 is known to be correlated with subjective feelings of fatigue [25] and we therefore interpret this finding as a logical consequence of the high prevalence of patients with fatigue in the study population. Patients with unexplained complaints do not seem to have predominantly psychosocial problems. The domains Social Functioning and Mental Health were not the worst scoring domains in the study population (mean 66.5 and 63.8 respectively). The Role Functioning Physical domain scored much lower (mean 37.2), suggesting that patients with unexplained complaints feel that their physical complaints hinder them in their daily functioning. Of the five categories of unexplained complaints, patients with unexplained fatigue have the poorest quality of life.

A first potential limitation of our study can be that different definitions and conceptualizations of unexplained complaints limit the generalizability of our findings. In our study, unexplained complaints were labelled "unexplained" by the GPs in the first consultation after onset, before more elaborate diagnostics. This is in contrast to 
medically unexplained symptoms (MUS), which refer to symptoms that have been ruled out to have an explainable cause (diagnosis by exclusion). Our concept of early stage unexplained complaints does not allow one to draw firm inferences as to whether the lower quality of life levels can be attributed to the unexplained complaints or should be attributed to underlying, though not yet diagnosed conditions, or concurrent comorbidity.

Second, we cannot fully exclude the possibility that some degree of selection bias is present. Participating GPs may have selectively included older patients or those with poorer quality of life. However, in a non-inclusion study in the participating general practices, we searched the electronic medical files by means of text words for eligible but not included patients with unexplained complaints. This non-inclusion study did not show major sex and age differences between included and not-included patients. However, differences may exist on other characteristics.

A third limitation of our study is that no specific depression or anxiety questionnaire was used. At the start of the study, such a poor quality of life was not anticipated and, therefore, only a more general questionnaire was considered sufficient. The RAND-36 mentally/emotionally oriented domain figures and the differences we found when comparing the quality of life profile of unexplained complaint patients with depressed patients however, are not pointing towards the presence of depression or anxiety. Furthermore, the GPs did not consider the included patients to be depressed or suffering from an anxiety disorder, otherwise they would not have labelled the patient as having unexplained complaints by definition. It is not impossible however, that depression or anxiety disorders might play a role in the poor quality of life of patients with unexplained complaints. Maybe these diagnoses are established only by GPs over time, and do not become clear in (one of) the first consultations.

Finally, the patient groups used for comparison of quality of life are perhaps not totally comparable to our study population. For example, there are older patients included in our study population than in the depressed patient groups. Since age has its influence on quality of life this can have influenced the contrast. Also, a depression is a treatable condition, whereas early stage unexplained complaints are not treated yet. The better quality of life in this patient group on some domains can therefore be a treatment effect. We did, however, not intend to study a fully comparable contrast in this sense beforehand, it was a result driven comparison.

Although much research has been performed in patients with more chronic consequences of unexplained complaints, to our knowledge, no other study on demographic characteristics and quality of life of patients with early stage unexplained complaints in general practice has been published.

Patients with unexplained complaints appear to be mainly highly educated women in their forties. They report remarkably poor levels of quality of life. Future research should explore whether and how quality of life scores and other characteristics could help in early identification of patients at risk of developing chronicity. Until then practitioners should at least be aware that early stage unexplained complaints may not always be as mild as is frequently assumed. Early stage unexplained complaints may be associated with considerable suffering on a daily basis. Awareness of potential poor quality of life may help physicians realise that they are dealing with a patient, at least, in need of more intense monitoring but maybe also of more intense treatment approaches.

Acknowledgements We would like to express our gratitude to all patients for participation and all GPs for their help in patient recruitment.

\section{References}

1. Dinant, G. J., van Wijk, M. A. M., Janssens, H. J. E. M., Somford, R. G., de Jager, C. J., Beusmans, G. H. M. I. et al. (1994). The DCGP guideline for blood testing [NHG-standaard Bloedonderzoek]. Huisarts \& Wetenschap, 37, 202-211.

2. van der Weijden, T., van Velsen, M., Dinant, G. J., van Hasselt, C. M., \& Grol, R. (2003). Unexplained complaints in general practice: Prevalence, patients' expectations, and professionals' test-ordering behavior. Medical Decision Making, 23(3), 226231.

3. Kenter, E. G., Okkes, I. M. (1999). Patients with fatigue in family practice: Prevalence and treatment. Ned Tijdschr Geneeskd, 143(15), 796-801.

4. Kenter, E. G. H., Okkes, I. M., Oskam, S. K., \& Lamberts, H. (2003). Tiredness in Dutch family practice. Data on patients complaining of and/or diagnosed with 'tiredness'. Family Practice, 20(4), 434-440.

5. Burton, C. (2003). Beyond somatisation: A review of the understanding and treatment of medically unexplained physical symptoms (MUPS). British Journal of General Practice, 53(488): 231-239.

6. Katon, W. J., \& Walker, E. A. (1998). Medically unexplained symptoms in primary care. Journal of Clinical Psychiatry, 59, 15-21.

7. Feder, A., Olfson, M., Gameroff, M., Fuentes, M., Shea, S., Lantigua, R. A., et al. (2001). Medically unexplained symptoms in an urban general medicine practice. Psychosomatics, 42(3), 261-268.

8. Hartz, A. J., Noyes, R., Bentler, S. E., Damiano, P. C., Willard, J. C., \& Momany, E. T. (2000). Unexplained symptoms in primary care: Perspectives of doctors and patients. General Hospital Psychiatry, 22(3), 144-152.

9. Lundh, C., Segesten, K., \& Bjorkelund, C. (2004). To be a helpless helpoholic - GPs' experiences of women patients with non-specific muscular pain. Scandinavian Journal of Primary Health Care, 22(4), 244-247.

10. Rosendal, M., Fink, P., Bro, F., \& Olesen, F. (2005). Somatization, heartsink patients, or functional somatic symptoms? 
Towards a clinical useful classification in primary health care. Scandinavian Journal of Primary Health Care, 23(1), 3-10.

11. Deary, I. J. (1999). A taxonomy of medically unexplained symptoms. Journal of Psychosomatic Research, 47(1), 51-59.

12. Burton, C. (2003). Beyond somatisation: A review of the understanding and treatment of medically unexplained physical symptoms (MUPS). British Journal of General Practice, 53(488), 231-239.

13. Feder, A., Olfson, M., Gameroff, M., Fuentes, M., Shea, S., Lantigua, R. A., et al. (2001). Medically unexplained symptoms in an urban general medicine practice. Psychosomatics, 42(3), 261-268.

14. Smith, G. R Jr., Monson, R. A., \& Ray, D. C. (1986). Patients with multiple unexplained symptoms. Their characteristics, functional health, and health care utilization. Archives of Internal Medicine, 146(1), 69-72.

15. Goldberg, D., Gask, L., \& O’Dowd, T. (1989). The treatment of somatization: Teaching techniques of reattribution. Journal of Psychosomatic Research, 33(6), 689-695.

16. Blankenstein, A. H. (2001). Somatising patients in general practice. Reattribution, a promising approach ( $\mathrm{PhD}$ Thesis) Amsterdam: Vrije Universiteit.

17. Fink, P., Rosendal, M., \& Toft, T. (2002). Assessment and treatment of functional disorders in general practice: The extended reattribution and management model-an advanced educational program for nonpsychiatric doctors. Psychosomatics, 43(2), 93-131.

18. van Bokhoven, M. A., Koch, H., van der Weijden, T., Grol, R. P., Bindels, P. J., \& Dinant, G. J. (2006). Blood test ordering for unexplained complaints in general practice: The VAMPIRE randomised clinical trial protocol [ISRCTN55755886]. BMC Family Practice, 7(1), 20.

19. Westert, G. P., Schellevis, F. G., De Bakker, D. H., Groenewegen, P. P., Bensing, J. M., \& van der Zee, J. (2005). Monitoring health inequalities through general practice: The Second Dutch National Survey of General Practice. European Journal of Public Health, 15(1), 59-65.

20. Ware, J. E., \& Sherbourne, C. D. (1992). The Mos 36-Item ShortForm Health Survey (Sf-36) .1. Conceptual-Framework and Item Selection. Medical Care, 30(6), 473-483.

21. Westert, G. P., Schellevis, F. G., De Bakker, D. H., Groenewegen, P. P., Bensing, J. M., \& van der Zee, J. (2005). Monitoring health inequalities through general practice: The Second Dutch National Survey of General Practice. European Journal of Public Health, 15(1), 59-65.

22. Wensing, M., Vingerhoets, E., \& Grol, R. (2001). Functional status, health problems, age and comorbidity in primary care patients. Quality of Life Research, 10(2), 141-148.

23. Kruijshaar, M. E., Hoeymans, N., Bijl, R. V., Spijker, J., \& Essink-Bot, M. L. (2003). Levels of disability in Major Depression Findings from the Netherlands Mental Health Survey and Incidence Study (NEMESIS). Journal of Affective Disorders, 77(1), 53-64.

24. Roger, W. H. (1993). Regression standard errors in clustered samples. Stata technical bulletin, 13, 19-23.

25. O'Connor, P. J. (2004). Evaluation of four highly cited energy and fatigue mood measures. Journal of Psychosomatic Research, 57(5), 435-441. 